\title{
Predicting Pasture Nitrogen Content using ANN Models and Thermal Images
}

\author{
$\underline{\text { M. Safa }}^{a}$ and T.M.R. Maxwell ${ }^{b}$ \\ ${ }^{a}$ Department of Land Management and Systems, Lincoln University, New Zealand \\ ${ }^{b}$ Department of Agricultural Sciences, Lincoln University, New Zealand \\ Email: Majeed.Safa@lincoln.ac.nz
}

\begin{abstract}
This study explored the possibility of estimating nitrogen content in a pasture grass using thermal images and artificial neural networks (ANN), based on the premise that plant herbage with a higher $\mathrm{N}$ content would be absorbing more light energy for active photosynthesis, therefore emitting excess energy as heat. This is the first reported study to use thermal infrared images and ANN to estimate pasture nitrogen content under different conditions of nitrogen $(\mathrm{N})$ fertiliser. The research was conducted in a controlledclimate environment to isolate the effect of a key environmental parameter, available soil $\mathrm{N}$, on pasture grass herbage temperatures. The project was the first step towards developing a smart fertiliser spreader to manage $\mathrm{N}$ applications based on plant temperature.
\end{abstract}

A small glasshouse pot experiment was conducted to determine the degree of the correlations between leaf $\mathrm{N}$ content and the surface temperatures of perennial ryegrass (Lolium perenne) herbage. Using a thermal imaging camera, periodic measurements of the herbage surface temperatures were made in conjunction with herbage cuts and analysis of grass dry matter for $\% \mathrm{~N}$ content. At the same time, other environmental factors, such as air temperature and humidity, were also measured.

As data constituted the core of the study, the database should be flexible, accessible and simple, for both data entry and data analysis. Subsequently, an ANN model was developed to predict N content based on herbage temperatures and the other factors measured. The final ANN model was developed based on three input variables: plant temperature, number of days after planting, and number of days after the last nitrogen application, with an error margin of \pm 0.93 and $\pm 0.87 \% \mathrm{~N}$ for the training and validation data, respectively. Comparing actual and predicted data showed that the ANN model could be fitted to pasture nitrogen content and accounted for around $84 \%$ and $92 \%$ of the variance in the training and validation data, respectively. The outcome of this study will aid the development of technology for estimating nitrogen content of perennial ryegrass (Lolium perenne) under field conditions which was seen as critical in the design of an advanced fertiliser spreader to manage nitrogen application on farms.

Keywords: $\quad$ Modelling, pasture, thermal images, nitrogen, artificial neural networks 


\section{INTRODUCTION}

The invisible radiation patterns of objects, when converted into visible images, are called thermal images (Ishimwe et al., 2014). Thermal sensors are used to obtain thermal images of any object for quantitative studies of different properties, such as those related to growth, yield and adaptation to biotic (disease, insects) or abiotic (drought and salinity) stress (Li et al., 2014). Thermal imaging systems comprise a thermal camera, a signal processing unit and an image acquisition system (Fitzgerald et al., 2006).

Due to their simple operational procedures, thermal imaging systems are widely used in many fields, such as agriculture, civil engineering, industrial maintenance, aerospace, medicine, pharmacy and veterinary science (Vadivambal \& Jayas, 2011). In fact, thermal imaging can be used to study the geometry and morphology of any agricultural material and process where heat is emitted or lost in space and time (Hellebrand et al., 2006).

The principle behind thermal imaging use was described well by da Luz and Crowley (2010) and (Tilling et al., 2007). The thermal properties of plant leaves are determined by internal leaf structures, which contain a certain amount of water per unit area (Hu et al., 2011). Plant chemical and spectral properties change with nutrients and water deficiency status (Fitzgerald et al., 2006). Thus, it is possible to judge the freshness status of different leaves and the nutrient content of various crops with thermal images. Use of reflected light to measure nitrogen (N) and water status has been well described by Blackmer et al. (1994), Gao (1995), Osborne et al. (2002) and Penuelas et al. (1993).

Thermal imaging provides rapid identification of crop N status (Al-Abbas et al., 1974; Schepers et al., 1996; Thomas \& Gausman, 1977). The response of a crop to $\mathrm{N}$ fertiliser applications is mostly dependent on plant available water. Therefore, it is essential to match $\mathrm{N}$ supply with spatial and temporal soil water availability, for which regular monitoring of plant available water and crop $\mathrm{N}$ status is essential (Tilling et al., 2007). This would allow targeted $\mathrm{N}$ applications only to areas of the crop with $\mathrm{N}$ stress (deficiency) but with sufficient plant available water. Modern thermal imaging techniques with high resolution allow for the visualisation of multi-dimensional and multi-parameter data ( $\mathrm{Li}$ et al., 2014). The use of thermal imaging techniques gives insight into dynamic responses to $\mathrm{N}$ applications and water stress (Li et al., 2014). Thus, thermal imaging provides relevant information for real time irrigation scheduling and the measurement of $\mathrm{N}$ concentrations (Fitzgerald et al., 2006).

Different spectral imaging technology has have been used to research $\mathrm{N}$ content in different plants. For example, Cabrera-Bosquet et al. (2010) used near infrared reflectance spectroscopy (NIRS) to predict the N content in maize grown under different water treatment conditions. The NIRS reflected genotypic differences in $\mathrm{N}$ content under each water treatment, confirming that NIRS can be used to predict $\mathrm{N}$ in maize to improve nitrogen and water use efficiency. Nguyen and Lee (2006) used hyperspectral canopy reflectance (300-1100 $\mathrm{nm}$ ) data recorded at various growth stages to develop a model for assessing $\mathrm{N}$ status in rice. The results revealed that an acceptable and accurate model can be developed using hyperspectral canopy reflectance data to predict $\mathrm{N}$ concentration and $\mathrm{N}$ density in rice. Tilling et al. (2007) used thermal imaging to quantify the $\mathrm{N}$ status of wheat under irrigated and rainfall conditions, at different levels of $\mathrm{N}$ application. Thermal images indicated that the mean plot temperature of rain-fed wheat was $6.5^{\circ} \mathrm{C}$ and this was $2.7^{\circ} \mathrm{C}$ warmer than the irrigated treatment during years 2004 and 2005, respectively. Apart from irrigation supply and plant cover, the plot temperature was also affected by $\mathrm{N}$ treatment, with lower temperature images at increased levels of $\mathrm{N}$ application (Tilling et al., 2007).

Haboudane et al. (2002) state that light reflected by plants is predominantly influenced by the chlorophyll present in the leaves, which has been found to relate to the concentration of leaf N. Measurement of reflected energy from crop leaves and canopies is, thus, an estimate of chlorophyll concentration and $\mathrm{N}$ concentration of the leaf. However, to a certain extent, plant cover, plant size, plant age, and leaf angle also affect the reflection of light from the plant leaf. Fitzgerald et al. (2006) claims that responses to applied $\mathrm{N}$ will be greater if the plant has low water stress. Under a non-limiting soil moisture content, a $\mathrm{N}$ deficiency would induce stomatal closure in different crop species, such as beans, wheat, sugar beets, maize, groundnuts (Shimshi, 1967).

A nitrogen deficiency can be determined by analysing the different colours in thermal images. For example, in fluorescence images, a higher blue-green, higher Chl-F at $690 \mathrm{~nm}$ (Corp et al., 2003; Heisel et al., 1996) and reduced chlorophyll concentration indicates a nitrogen deficiency (Liu et al., 2000). Different crops respond differently to different amounts of nitrogen fertiliser use (Costa et al., 2013). According to Chaerle et al. (2007), thermal imaging of spring barley indicated a higher canopy temperature in crops subjected to no $\mathrm{N}$ fertiliser use compared to those receiving $165 \mathrm{~kg} \mathrm{~N} \mathrm{ha}^{-1}$ use. However, the opposite was true for wheat plants (Tilling et al., 2007). Following the principle underlying chlorophyll florescence analysis (Maxwell \& Johnson 2000) that light energy absorbed by chlorophyll molecules in a leaf can undergo three fates: 1 - 
energy utilised to drive photosynthesis, 2 - excess energy dissipated as heat, or 3 - re-emitted as lightchlorophyll fluorescence, It was hypothesized that plant herbage with a higher $\mathrm{N}$ content would be absorbing more light energy for active photosynthesis, therefore emitting less excess energy as heat. More research is needed in this area to ascertain the degree of the link between plant leaf temperature and leaf $\% \mathrm{~N}$ content (a function of available $\mathrm{N}$ supply).

Artificial neural networks (ANN) are becoming a common tool for modelling complex input-output dependencies (Parten et al., 1990; Safa \& Samarasinghe, 2013; Samarasinghe, 2007). ANNs learn the link between the input and output variables by studying previously recorded data (Kalogirou, 2000). Therefore, the size and accuracy of the data sample is the critical part of the model, because without enough samples, ANNs cannot create the correct connections; sample sizes can vary from just a a few up to thousands in complex projects. The benefits of using ANN models are the simplicity of application and the robustness of the results. ANNs have developed into a powerful approach that can approximate any nonlinear input-output mapping function to any degree of accuracy and in an iterative manner. ANNs have many attractive properties for modelling complex production systems. Some of these are: universal function approximation capability, resistance to noisy or missing data, accommodation of multiple non-linear variables with unknown interactions, and good generalisation ability (Hagan et al., 2002).

\section{METHODS}

This is the first reported study to use thermal infrared images and an ANN model to estimate nitrogen content in pasture. A small glasshouse pot $(33 \mathrm{~cm} * 42 \mathrm{~cm})$ experiment was conducted to determine the degree of the correlation between leaf $\mathrm{N}$ content and the surface temperature of perennial ryegrass (Lolium perenne) herbage. The study was developed in a controlled environment to isolate the effect of soil $\mathrm{N}$ supply on the herbage leaf surface temperature. Using a thermal imaging camera, periodic measurements of herbage surface temperatures were made in conjunction with herbage cuts and herbage dry matter analysis for $\% \mathrm{~N}$ content. At the same time, other environmental factors, such as humidity and air temperature, were measured. The pots were watered daily and the plant temperature was measured one hour after watering the pot to minimise the effect of soil moisture on plant temperature. In this study a Flir E30 thermal camera with spectral range between 7.5 and $13 \mu \mathrm{m}$ were used to measure the plant temperatures.

Ryegrass plants were established at a population rate of 1000 plants per $\mathrm{m}^{2}$ in a no-N soil medium (138 plants per pot). Three soil $\mathrm{N}$ treatments were created by spreading urea onto the soil medium surface at rates equivalent to 50,100 , and $300 \mathrm{~kg} \mathrm{~N} / \mathrm{ha}$. Periodic measurements of the surface temperature of the herbage were made using a mobile platform from which infrared measurements of the herbage temperature were made from $1 \mathrm{~m}$ above the pots. The emissivity value of thermal images was selected as $95 \%$.

For data analysis, the thermal images were analysed using Flir software to find the average temperature of the leaves (Figure 1). The soil surface temperature would change the accuracy of the data measurement, therefore, only the average temperature of the areas covered by plants were measured. As data constituted the core of the study, the database should be flexible, accessible and simple for both data entry and data analysis. Subsequently, after five monthly herbage cuts, an ANN model was developed to predict leaf $\mathrm{N}$ content based on herbage temperatures and the other factors measured. In this study, $\mathrm{N}$ fertiliser was applied twice as urea. The first application was 15 days after ryegrass seedling emergence, and the second application was three months after the first $\mathrm{N}$ application.

In most studies, a feed-forward multi-layered perception (MLP) paradigm, consisting of one or more inputs, hidden layers and an output layer trained by back propagation learning method (BP), have been used (Heinzow \& Tol 2003; Hornik et al., 1989; Jebaraj \& Iniyan, 2006). In the processing of inputs by the network, each neuron in the first layer (hidden layer) processes the weighted inputs through a transfer function to produce an output. The transfer functions may be a linear or nonlinear function. Some popular transfer functions include: Logistic, Hyperbolic-tangent, Gaussian and Sine. The output of a neuron depends on the particular transfer function used. This output is then sent to the neurons in the next layer through weighted connections and these neurons complete their outputs by processing the sum of the weighted inputs through their transfer functions. When this layer becomes the output layer, the neuron output becomes the predicted output.

Weights are adjusted to minimise the mean square error (MSE) between the predicted outputs and targets. The MSE, the most commonly used error indicator of the prediction over all the training patterns for a network with one output neuron, can be written as: 


$$
M S E=\frac{1}{N} \sum_{i}^{N}\left(t_{i}-z_{i}\right)^{2}
$$

where $t_{i}$ and $z_{i}$ are the target and the predicted output for the ith training pattern, $N$ is the total number of training patterns (Samarasinghe, 2007). The root mean square error (RMSE) is another error estimation that shows the error in the units of the target and predicted data.

After several trials using Peltarion Synapse software, a modular neural network with two hidden layers was developed in this study. Quick Prop was used as the learning method because of its speed in reducing the errors and finding the best model. Quick Prop implicitly uses the second derivative of error to adjust weights (Equations 2, 3 and 4). In each iteration of Quick Prop, the update for the weights was regulated, as follows:

$$
\begin{aligned}
& w_{m+1}=w_{m}+\Delta w_{m} \\
& \Delta w_{m}=\frac{d_{m}}{d_{m-1}-d_{m}} \Delta w_{m-1} \\
& d_{m}=\sum_{n-1}^{N}\left[\frac{\partial E}{\partial w_{m}}\right]_{n}
\end{aligned}
$$

where $\Delta w_{m}$ is the current weight increment, $d_{m}$ is the average derivative of the error with respect to the weight for the current epoch $\mathrm{m}$; and $\partial E / \partial w_{m}$ is the current error gradient for a particular input vector (Samarasinghe, 2007).

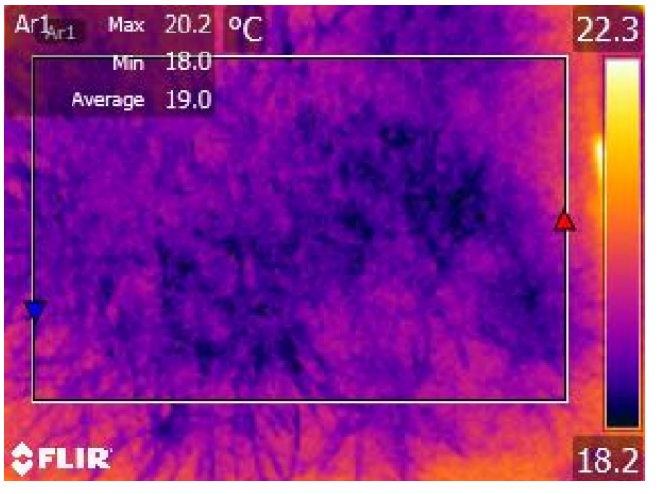

Figure 1. Thermal image of a pot before a monthly herbage cut.

After testing different learning algorithms, neuron activation functions and network structures, a modular network with two hidden layers was developed, as shown in Figure 2. In the modular network structure, the model was characterised by a series of independent neural networks after the input layer, which operated on the inputs to achieve several subtasks of the task the network expected to perform. These subtasks were trained separately using different examples from the samples and their outputs were summed in the output layer. This structure of the model made it possible for the network to simultaneously use different neuron activation functions. In the final model, a Sine function was used for the input layer; a hyperbolic tangent function was selected for the output layer and the first hidden layer, and a logistic function was applied for second hidden layer (Figure 2).

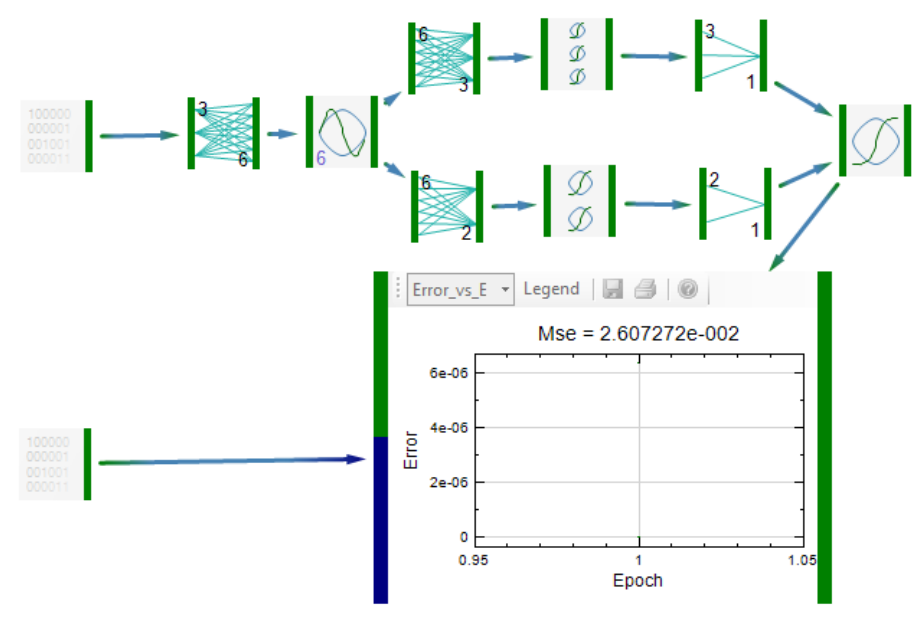

Figure 2. Structure of the modular network and number of neurons in each layer.

\section{RESULTS}

After 6800 iterations, the ANN model achieved the best results with a scaled MSE $=2.61 \backslash \mathrm{E}-2$ (inputs and outputs were scaled between -1 and +1 for the neural networks model). The actual RMSE of the final ANN 
model was estimated to be $0.41 \% \mathrm{~N}$ and $0.38 \% \mathrm{~N}$ for the training and validation data, respectively. This was the lowest RMSE between several ANN models examined in this study. As shown in Figures 3 and 4, the \% $\mathrm{N}$ estimated by the ANN accounted for $93 \%$ and $94 \%$ of the actual variability in $\% \mathrm{~N}$ in training and validation data, respectively.

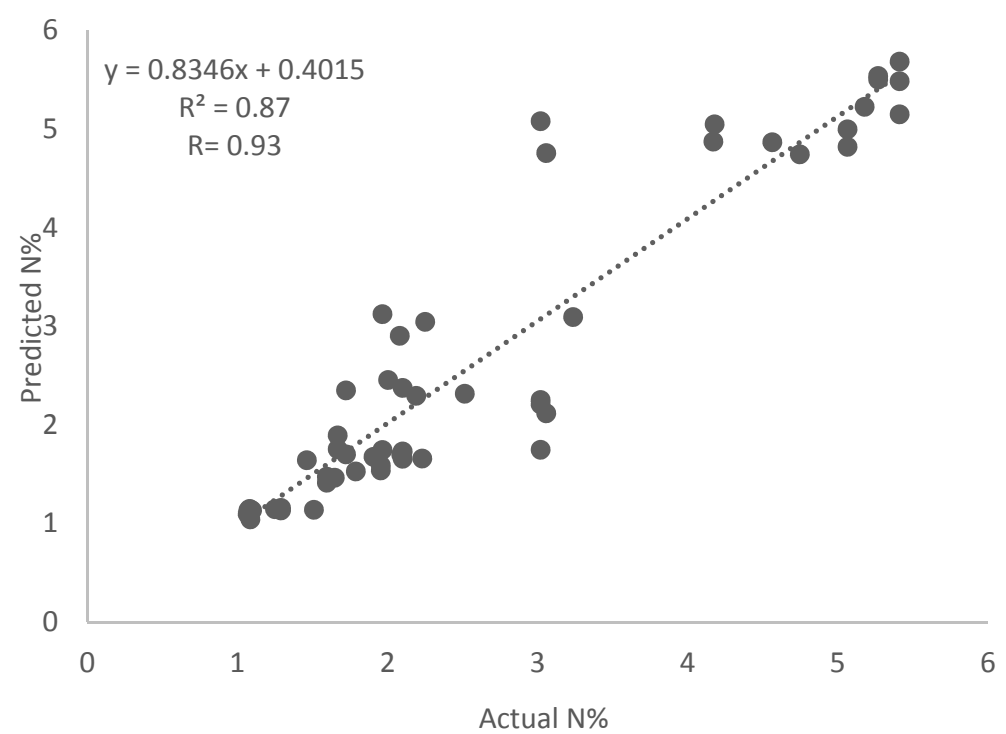

Figure 3. Relationships between observed and predicted pasture nitrogen content (Training) using the artificial neural networks model.

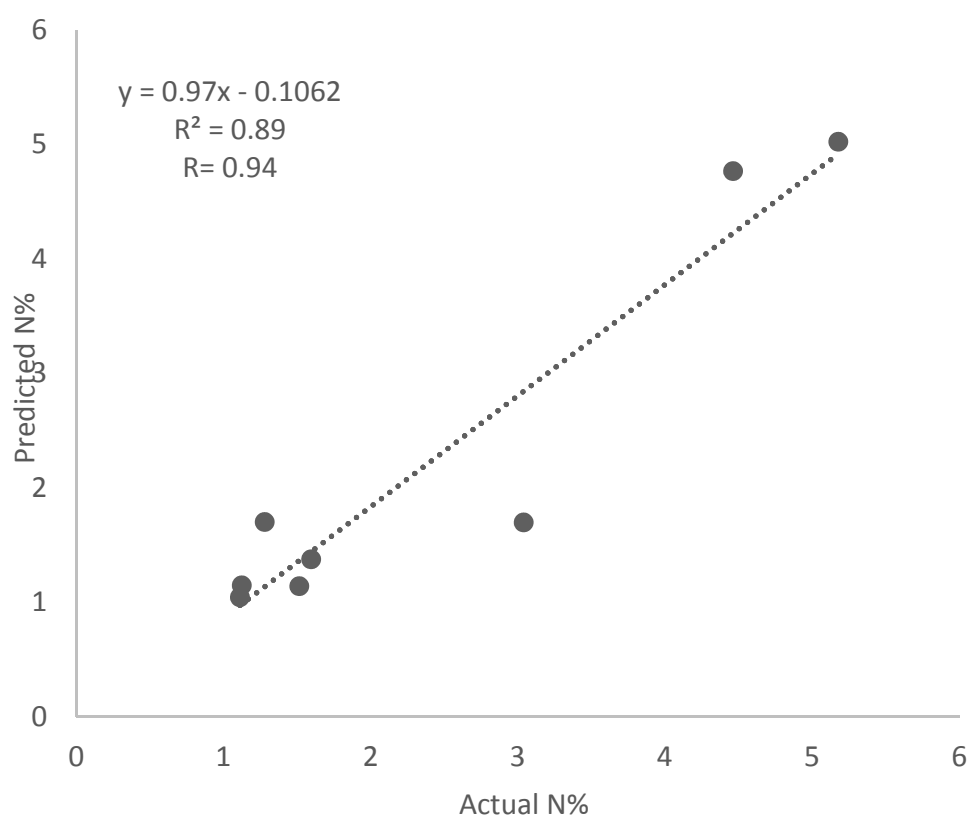

Figure 4. Relationships between observed and predicted pasture nitrogen (Validation) using the artificial neural networks model.

As shown in Figure 5, the final model predicted pasture nitrogen content with an error margin of $\pm 0.93 \% \mathrm{~N}$ (training data). Comparing the training and validation data showed that the correlation between predicted and actual $\% \mathrm{~N}$ in both training and validation data were similar. It is recommended other input variables should be examined to improve the model under different conditions. There were several factors which could influence the final results; however, the result of this study was very encouraging and the final model can predict pasture nitrogen content with an acceptably low error. 


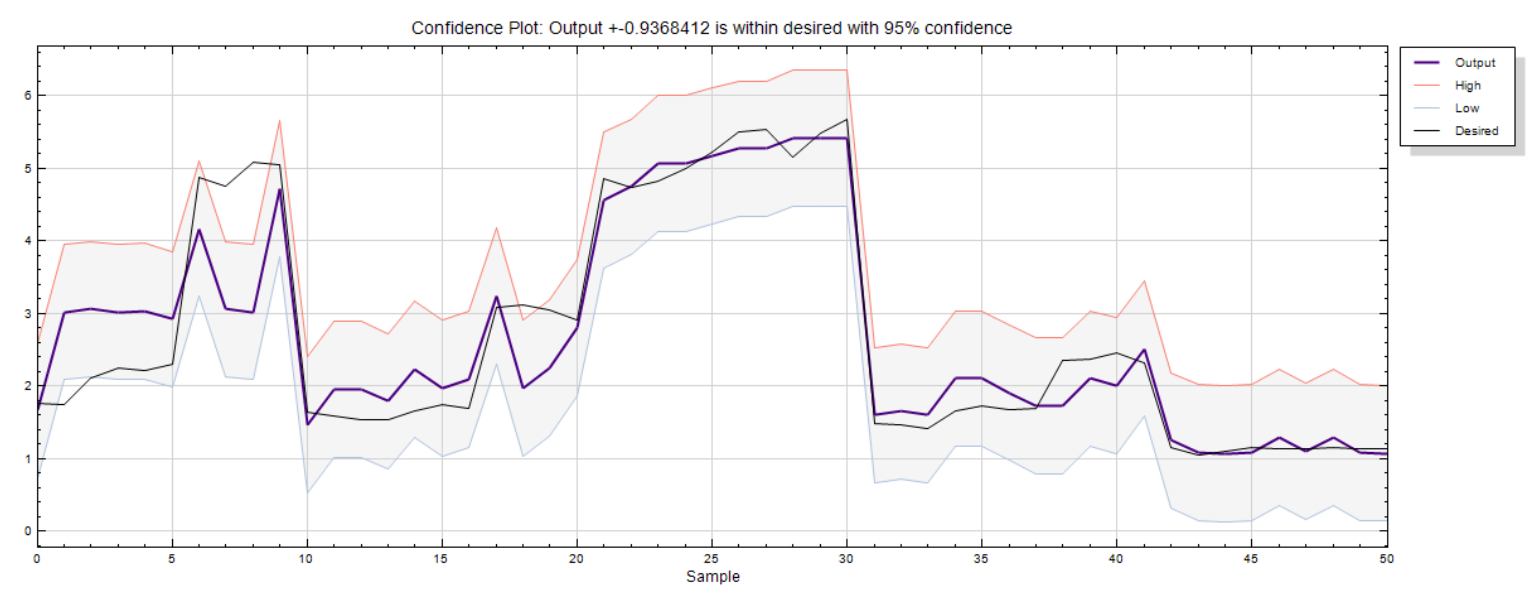

Figure 5. Predicted (dark-blue), observed (black), and the $95 \%$ confidence interval (grey region), for the pasture nitrogen content based on the artificial neural networks model (training data).

\section{CONCLUSIONS}

This study has shown it was possible to estimate nitrogen content of perennial ryegrass (Lolium perenne) herbage under different soil $\mathrm{N}$ fertility conditions in a controlled environment (glasshouse conditions). The results showed that an ANN model with basic input variables was capable of predicting pasture nitrogen content within acceptable errors. The accuracy of the data was a critical factor in developing a prediction model with a minimum margin of error. The final model predicted pasture nitrogen content $(\% \mathrm{~N})$ based on plant temperature, number of days after planting, and number of days after the last nitrogen application with an error margin of \pm 0.92 and $0.87 \% \mathrm{~N}$ for training and validation respectively. The main Table 1. MSE and RMSE for training and validation ANN model challenge of this method is collecting accurate data under farming conditions in the field.

\begin{tabular}{|l|ll|}
\hline & Training & Validation \\
\hline MSE & 0.166 & 0.143 \\
RMSE & 0.407 & 0.379 \\
\hline
\end{tabular}

It is possible to use the hypothesis of the current project in an advanced precision farming project to reduce nitrogen consumption by using thermal images, artificial neural networks, and machine vision to improve fertiliser use efficiency. Adding other input variables, such as soil moisture, soil temperature, and air humidity, would improve the accuracy of the model. The study has great potential to reduce nitrogen consumption, farmers' costs and environmental impacts on New Zealand dairy farms.

The method used in this study can be developed for other plants and agricultural products. Future studies to compare other modelling methods and other input variables are strongly recommended.

\section{ACKNOWLEDGMENTS}

The project was funded by the Lincoln University early career research award (ECR). The authors acknowledge the efforts of Lincoln University. We are also grateful to greenhouse and laboratory staff of Lincoln University for their help and support.

\section{REFERENCES}

Al-Abbas, A., Barr, R., Hall, J., Crane, F., \& Baumgardner, M. (1974). Spectra of normal and nutrient-deficient maize leaves. Agronomy Journal, 66(1), 16-20.

Blackmer, T. M., Schepers, J. S., \& Varvel, G. E. (1994). Light reflectance compared with other nitrogen stress measurements in corn leaves. Agronomy Journal, 86(6), 934-938.

Cabrera-Bosquet, L., Sánchez, C., Rosales, A., Palacios-Rojas, N., \& Araus, J. L. (2010). Near-Infrared Reflectance Spectroscopy (NIRS) Assessment of $\delta 180$ and nitrogen and ash contents for improved yield potential and drought adaptation in maize. Journal of agricultural and food chemistry, 59(2), 467-474.

Chaerle, L., Hagenbeek, D., Vanrobaeys, X., \& Van Der Straeten, D. (2007). Early detection of nutrient and biotic stress in Phaseolus vulgaris. International Journal of Remote Sensing, 28(16), 3479-3492.

Corp, L. A., McMurtrey, J. E., Middleton, E. M., Mulchi, C. L., Chappelle, E. W., \& Daughtry, C. S. (2003). Fluorescence sensing systems: In vivo detection of biophysical variations in field corn due to nitrogen supply. Remote sensing of environment, 86(4), 470-479. 
Costa, J. M., Grant, O. M., \& Chaves, M. M. (2013). Thermography to explore plant-environment interactions. Journal of experimental botany, 64(13), 3937-3949.

Da Luz, B. R., \& Crowley, J. K. (2010). Identification of plant species by using high spatial and spectral resolution thermal infrared (8.0-13.5 $\mu \mathrm{m})$ imagery. Remote Sensing of Environment, 114(2), 404-413.

Fitzgerald, G., Rodriguez, D., Christensen, L., Belford, R., Sadras, V. O., \& Clarke, T. (2006). Spectral and thermal sensing for nitrogen and water status in rainfed and irrigated wheat environments. Precision Agriculture, 7(4), 233-248.

Gao, B.-C. (1995). Normalized difference water index for remote sensing of vegetation liquid water from spaceInternational Society for Optics and Photonics. Symposium conducted at the meeting of the SPIE's 1995 Symposium on OE/Aerospace Sensing and Dual Use Photonics

Haboudane, D., Miller, J. R., Tremblay, N., Zarco-Tejada, P. J., \& Dextraze, L. (2002). Integrated narrow-band vegetation indices for prediction of crop chlorophyll content for application to precision agriculture. Remote sensing of environment, 81(2), 416-426.

Hagan, M., Demuth, H., \& Beale, M. (2002). Neural network design: Boston, USA: PWS Publishing Company.

Heinzow, T., \& Tol , R. S. J. (2003). Prediction of crop yields across four climate zones in Germany: an artificial neural network approach. Centre for Marine and Climate Research, Hamburg University, Hamburg.

Heisel, F., Sowinska, M., Miehé, J. A., Lang, M., \& Lichtenthaler, H. K. (1996). Detection of nutrient deficiencies of maize by laser induced fluorescence imaging. Journal of plant physiology, 148(5), 622-631.

Hellebrand, H., Herppich, W., Beuche, H., Dammer, K., Linke, M., \& Flath, K. (2006). Investigations of plant infections by thermal vision and NIR imaging. International agrophysics, 20(1), 1.

Hornik, K., Stinchocombe, M., \& White, H. (1989). Multilayer feedforward networks are universal approximators. Elsevier Science Ltd. Oxford, UK, UK 2(5).

$\mathrm{Hu}, \mathrm{Z} ., \mathrm{Du}, \mathrm{W} ., \mathrm{\&} \mathrm{He}, \mathrm{X}$. (2011). Application of infrared thermography technology for irrigation scheduling of winter wheatIEEE. Symposium conducted at the meeting of the Multimedia Technology (ICMT), 2011 International Conference on

Ishimwe, R., Abutaleb, K., \& Ahmed, F. (2014). Applications of Thermal Imaging in Agriculture-A Review. Advances in Remote Sensing, 3(03), 128.

Jebaraj, S., \& Iniyan, S. (2006). A review of energy models. Renewable and Sustainable Energy Reviews, 10(4), 281-311. doi:10.1016/j.rser.2004.09.004

Kalogirou, S. A. (2000). Applications of artificial neural-networks for energy systems. Applied Energy, 67(1-2), 17-35. doi:10.1016/s0306-2619(00)00005-2

Li, L., Zhang, Q., \& Huang, D. (2014). A Review of Imaging Techniques for Plant Phenotyping. Sensors, 14(11), 2007820111.

Liu, Q., Gu, X., Li, X., Jacob, F., Hanocq, J., Friedl, M., Etrahler, A,H,. Yu,T,. Tian, G. (2000). Study on thermal infrared emission directionality over crop canopies with TIR camera imagery. Science in China Series E: Technological Sciences, 43(1), 95-103.

Maxwell, K., Johnson, G. N. (2000). Chlorophyll fluorescence - a practical guide. Journal of Experimental Botany, 51 (345), 659-668.

Nguyen, H. T., \& Lee, B.-W. (2006). Assessment of rice leaf growth and nitrogen status by hyperspectral canopy reflectance and partial least square regression. European Journal of Agronomy, 24(4), 349-356.

Osborne, S., Schepers, J. S., Francis, D., \& Schlemmer, M. R. (2002). Detection of phosphorus and nitrogen deficiencies in corn using spectral radiance measurements. Agronomy Journal, 94(6), 1215-1221.

Parten, C., Hartson, C., \& Maren, A. (1990). Handbook of neural computing applications: San Diego, CA (USA); Academic Press Inc.

Penuelas, J., Filella, I., Biel, C., Serrano, L., \& Save, R. (1993). The reflectance at the 950-970 nm region as an indicator of plant water status. International journal of remote sensing, 14(10), 1887-1905.

Safa, M., \& Samarasinghe, S. (2013). Modelling fuel consumption in wheat production using artificial neural networks. Energy, 49, 337-343.

Samarasinghe, S. (2007). Neural networks for applied sciences and engineering : from fundamentals to complex pattern recognition. Boca Raton, FL: Auerbach. Retrieved from http://www.loc.gov/catdir/toc/ecip0610/2006007625.html

Schepers, J. S., Blackmer, T., Wilhelm, W., \& Resende, M. (1996). Transmittance and Reflectance Measurements of CornLeaves from Plants with Different Nitrogen and Water Supply. Journal of Plant Physiology, 148(5), 523529.

Shimshi, D. (1967). Leaf Chlorosis And Stomatal Aperture*. New Phytologist, 66(3), 455-461.

Thomas, J., \& Gausman, H. (1977). Leaf reflectance vs. leaf chlorophyll and carotenoid concentrations for eight crops. Agronomy journal, 69(5), 799-802.

Tilling, A. K., O’Leary, G. J., Ferwerda, J. G., Jones, S. D., Fitzgerald, G. J., Rodriguez, D., \& Belford, R. (2007). Remote sensing of nitrogen and water stress in wheat. Field Crops Research, 104(1), 77-85.

Vadivambal, R., \& Jayas, D. S. (2011). Applications of thermal imaging in agriculture and food industry-a review. Food and Bioprocess Technology, 4(2), 186-199. 